\title{
The interaction between donor-conceived families and their environment: parents' perceptions of societal understanding and attitudes regarding their family-building
}

\section{Astrid Indekeu \& Claudia Lampic}

To cite this article: Astrid Indekeu \& Claudia Lampic (2018): The interaction between donorconceived families and their environment: parents' perceptions of societal understanding and attitudes regarding their family-building, Human Fertility, DOI: 10.1080/14647273.2018.1533256

To link to this article: https://doi.org/10.1080/14647273.2018.1533256

曲 Published online: 02 Nov 2018.

Submit your article to this journal $\pi$

View Crossmark data $₫$ 


\title{
The interaction between donor-conceived families and their environment: parents' perceptions of societal understanding and attitudes regarding their family-building
}

\author{
Astrid Indekeu ${ }^{\mathrm{a}, \mathrm{b}}$ and Claudia Lampic ${ }^{\mathrm{a}, \mathrm{c}}$ \\ ${ }^{a}$ Department of Neurobiology Care Sciences and Society, Karolinska Institutet, Huddinge, Sweden; ${ }^{b}$ Department of Sociology, \\ University of Leuven, Leuven, Belgium; 'Department of Women's and Children's Health, Karolinska Institutet, Stockholm, Sweden
}

\section{ABSTRACT}

Disclosure issues in relation to donor conception have mainly been examined in the context of relationships and interaction within donor-conceived families, whilst influences from outside the family, for example societal ones, have been little researched. This study explored the societal experiences of individuals who build their family with the help of donor conception (i.e. donorconceived families), specifically, where and how parents and society interact and the presence and influence of cultural beliefs and values regarding the family. Belgian $(n=89)$ and Swedish $(n=56)$ donor-conceiving parents completed an online-survey focusing on their experiences with societal perceptions and attitudes and behaviour and responses from friends, healthcare professionals and teachers. Descriptive and comparative statistical analyses were conducted. Results showed that donor-conceiving parents were challenged by societal representations, responses from friends, healthcare professionals and teachers, and cultural norms and values. Parents had to cope with lack of knowledge and understanding of donor-conceived families and colliding views on the relevance of genes in kinship. They needed to be able to explain and defend themselves, correct others and handle emotions and sensitivity when managing these interactions. Through psycho-education health-care professionals can help families anticipate potential reactions and manage societal responses by strengthening parents' coping mechanisms. These findings also call for awareness of the presence of cultural norms and values even when counsellor and patient share the same culture because counsellor and donor-conceiving parents can relate differently to (collide or conform with them) the shared cultural norms, which can impact on parents' experience.
ARTICLE HISTORY

Received 27 May 2018

Accepted 21 August 2018

KEYWORDS

Donor conception; donor-conceived families; society; attitudes; behaviour; responses

\section{Introduction}

While the science of assisted reproduction necessarily concentrates on the couple, or even the woman who will carry the pregnancy, family-building through donor conception is not solely a matter for the central couple but occurs within a complex network of relationships (Nordqvist \& Smart, 2014, p.8). Although Nordqvist and Smart (2014) focused primarily on the extended family network, as they included grandparents and other relatives outside the nuclear family in their research, wider social networks can also potentially be influential to donor-conceived families. Whereas, in the past, donor-conceived families lived in a rather silencing society, nowadays openness in donor conception is more and more encouraged by professional organizations and/or law (ESHRE Task Force on Ethics \& Law, 2002; Ethics Committee of the
American Society for Reproductive Medicine, 2004; Human Fertilisation \& Embryology Act, 2008; The Genetic Integrity Act, 2006). Societies too address more openly the themes of infertility and assisted reproductive technologies (ARTs) and the policies of donor conception technologies are nowadays publicly debated and covered in the media. Moreover, as the number of disclosing parents increases, parents (and children) are likely to talk to people outside the family unit, such as extended family, healthcare professionals and teachers (Golombok et al., 1996; Lalos, Gottlieb, \& Lalos, 2007).

Social networks can potentially be supportive and/ or stressful for donor-conceived families and can consequently influence families' well-being and how knowledge of and information about, donor conception is managed within the family. Cultural elements

CONTACT Astrid Indekeu astrid.indekeu@kuleuven.be $\Theta$ Department of Sociology, Centre for Sociological Research, University of Leuven, Parkstraat 45, box 3601, Leuven B-3000, Belgium

(C) 2018 The British Fertility Society 
such as a liberal socio-legal-cultural context (laws, values and norms about what constitutes 'a family', what defines 'a parent') have been suggested to influence donor conceiving parents' behaviour and experiences (Indekeu et al., 2013). On the one hand the increasing prevalence and acceptance of ARTs, the presence of diverse, non-traditional family structures (e.g. adopted, single parent, gay/lesbian, multiracial, multicultural family structures) and a politically liberal environment contribute to a decreased concern about stigma in these families (Hudson, Culley, Rapport, Johnson, \& Bharadwaj, 2009; Shehab et al., 2008; SöderströmAnttila, Sälevaara, \& Suikkari, 2010). On the other hand, while there might be a trend towards enhanced acceptance of non-traditional family structures and of ARTs, there is simultaneously a predominant Western societal discourse that families should be based on a biological connection, coupled with a revived interest in genetics due to developments in this field (Finkler, 2001; Franklin, 2013; Strathern, 1992). Normative models, being shared ideas and norms within a culture, of kinship, family and parenthood through public discourses have the potential to subject donor-conceived families to stigma. Researchers have reported on feelings of stigma, shame and fear of societal rejection impacting on parents' decision to disclose the donor conception to the offspring and/or others (Hahn \& Craft-Rosenberg, 2002; Hargreaves \& Daniels, 2007; Nachtigall, Tschann, Quiroga, Pitcher, \& Becker, 1997; Thorn \& Daniels, 2007) and the challenges donor-conceiving parents experience when coping with conversations/remarks about physical resemblance between parents and their children, referred to as "resemblance talk" (Becker, Butler, \& Nachtigall, 2005) or prevailing societal norms or ideologies regarding motherhood/ fatherhood, genetics and family/kinship (BirenbaumCarmeli, 2010; Gunnarsson-Payne, 2016; Kirkman, 2008). Norms and values can arise in various ways: in daily conversation (Becker et al., 2005), media representation (Adrian, 2010; Crabb \& Augoustinos, 2008; Gannon, Glover, \& Abel, 2004; Holohan, 2012) or national policies (Birenbaum-Carmeli, 2010). These societal norms and values may not only influence how society members behave towards those individuals affected by them, possibly resulting in stigmatizing behaviour. These community constructs/ideas may also affect how donor-conceiving people perceive themselves, potentially leading to perceived stigma. On a more personal interactional level three factors have been described which impact individuals' decision to disclose information regarding their infertility within their social network (Steuber \& Solomon, 2011).
Firstly, people estimate the consequences of the disclosure for themselves, their relationship and others such as their partner, their child. Consequences could be for example being socially rejected, laughed at, bullied. This first factor was referred to as risk assessment. Secondly, they evaluate how confident they feel in discussing the topic with others and managing the responses (referred to as confrontation efficacy). And thirdly, they evaluate how much they trust the other person (termed closeness in relationships).

Knowledge about the societal responses donorconceived families receive is vital to parents' understanding and management of their family-building, not only for themselves but also to enable them to support and coach their donor-conceived offspring. It is also crucial to health-care professionals, who are in a vital/ key position when it comes to assisting intending parents and parents in managing the complex relationships and dynamics they face when building their family with the assistance of a donor and to facilitate among other things by acknowledging the impact of stigma - confident and competent parenthood and families who are able to be open about their familybuilding (Crawshaw \& Montuschi, 2014; Daniels, Thorn, \& Westerbrooke, 2007).

Given the potential influence of social networks, the study objectives were to assess: (i) the perception of societal presence and representations of donor-conceived families; (ii) interaction behaviour of donor-conceiving parents; (iii) societal responses donorconceiving parents receive; (iv) attitudes regarding disclosure to others; and (v) perceived societal attitudes.

This study took place in two countries, Belgium (BE) and Sweden (SE), to explore if differences could be observed in societal perceptions between countries with different policies regarding donor conception. These countries have similar basic regulations regarding the technologies of donor conception, permitting treatments with donated sperm or eggs to heterosexual and lesbian couples, as well as to single women. At the same time they differ in some aspects of their regulation. Sweden abolished donor anonymity in 1985 , being the first country in the world to do so. The fundamental principle guiding this decision emphasized the rights and interests of children to access their ancestry. Policy guidelines also instruct fertility clinics to encourage disclosure of the donor conception to the donor offspring. In contrast, Belgium has a policy of donor anonymity and there are no recommendations on disclosure in law or guidelines for good practice. Respect for the privacy of donors and the privacy and authority of intending 
parents are mentioned as guiding principles of the law. It could be argued that a culture that promotes openness (identifiable donors, disclosure) might enhance the integration of donor-conceived families into society.

\section{Materials and methods}

Due to the continuous interplay between societies and donor-conceived families the study was set up using a 'dual-approach' inquiring into the experiences of donor-conceived families as well as members of society. This paper reports on perceptions from donorconceived families. The experiences of teachers, as members of society are to be covered elsewhere (manuscript under review).

\section{Measures}

Based on the results of preparatory explorative qualitative interviews, literature on theoretical concepts, and clinical experiences, a study-specific online questionnaire was developed covering the following areas:

Perception of societal presence and representations: Because donor-conceived families have long been hidden in society, participants were asked about the presence of the topic of donor-conceived families in society and how donor-conceived families were represented. One item inquired 'Where did you read, hear or see something about the topic?'. Thirteen response options were provided and multiple answers were possible. An open-response question followed asking 'Describe briefly what your most persistent impression is of how donor-conceived families are presented'.

Personal behaviour and societal responses: Participants' behaviour was assessed by asking if they had talked about the topic of donor conception with others. Subsequently multi-response questions inquired whom they had talked with, what topics were covered and what kind of reactions they had received. Several categories were given as well as the option 'other' that could be further clarified by the participant.

Personal and perceived societal attitudes: A first part asked participants to rate four statements regarding talking about donor conception on a scale from 0 [not agree] to 100 [fully agree]. The second part assessed perceived stigma using an adapted version of the perceived stigma scale from the Feelings About Adoption Scale (FAAS) (Goldberg, Kinkler, \& Hines, 2011). The five items were adapted for donor-conceived families. For all items, participants indicated on a five-point scale the extent to which each item applied to them $(1=$ not at all true to $5=$ very true). The internal consistency score, measured by Cronbach alpha scores, in our study was 0.74 for Swedish parents and 0.65 for Belgian parents. Items are summed and averaged to create a mean score for each participant.

\section{Data-analysis}

In keeping with the exploratory nature of this study, descriptive statistics were used. Mann-Whitney U-tests were computed to test for significant differences in distribution between Belgian and Swedish participants. Pearson's Chi-square tests or Fisher's exact tests were computed to test for differences in frequencies between the study groups. The level of significance was set at a $p$-value $<0.05$. Responses to the open questions were thematically analyzed (Hennink, Hutter, \& Bailey, 2011).

\section{Procedure}

Announcements of the study with a link to the onlinesurvey were placed on websites of consumer groups, Facebook pages or newsletters for people with infertility problems (BE: De verdwaalde Ooievaar; SE: Barnlängtan, Vilhabarn), consumer groups for donorconceived families (BE: Donorfamilies, Donorkinderen, Donorkind; SE: Scandinavian Seed Siblings) and Lesbian Gay Bisexual Transgender-family consumer groups (BE: Çavaria, Het Roze Huis; SE: Riksförbundet För Sexuellt Likaberättigande), through the websites of the universities (BE: KU Leuven; SE: Karolinska Institutet) and fertility clinics in Belgium (UZ Leuven, University Hospital Ghent). Before starting the survey, an electronic informed consent containing information about confidentiality and anonymity of their participation was provided. After giving informed consent, participants could start the survey which included questions with single and multiple answer possibilities as well as open-ended questions. Closed questions were compulsory to answer before being able to move to the next question. Participants' responses on a preceding item determined the next question. Consequently not all participants received the same number of questions. The total number of questions participants received ranged between 51 and 65 . If surveys had not been completed, two weeks after their last activity their survey was closed and the answers they had provided were recorded. The survey was administered online in Belgium and Sweden from 
January until May 2017. After completion of the survey, participants could sign up to enter a lottery in which one gift-voucher worth 50Euro/500 SEK was raffled per 50 participants. The study was approved by the Social and Societal Ethics Committee, University of Leuven, Belgium (Reference No. G-2016 08 613) and the Ethical Review Board Stockholm, Sweden (Reference No. 2016/2287-32).

\section{Participants}

Inclusion criteria were: (i) those seeking donor conception treatment (i.e. intending parents) or (ii) those who became a parent by relying on donor conception to build their family (i.e. donor-conceiving parents). Inclusion was independent of the type of donation (sperm, oocyte or embryo) or family-type (one or two parent household, same-sex or heterosexual parents). In Belgium participation was limited to Dutch-speaking participants. Eighty-nine Belgian and 56 Swedish (intending) parents took part in the study. In Belgium $12.7 \%(13 / 102)$ and in Sweden $16.4 \%(11 / 67)$ participants accessed the survey but did not proceed further. Participants' characteristics are presented in Table 1. Swedish participants were significant older $(p<0.001)$ and the group consisted of significantly $(p<0.001)$ more single donor-conceiving mothers than the Belgian group and more donor-conceiving parents who went abroad for treatment $(p<0.001)$. The Belgian group consisted of significantly more oocyte recipients $(p<0.05)$.

\section{Results}

\section{Perception of societal presence and representations of donor-conceived families}

The majority of Belgian and Swedish participants indicated that the topic of donor conception was widespread in the community through a variety of avenues. Belgian and Swedish participants shared almost the same top five cited sources of information, with 'the internet/blogs' being the most frequent mentioned source (BE: 71.9\%; SE: 66.1\%), followed by 'conversation with colleagues, friends and family' (BE: $66.3 \%$; SE: $44.6 \%$ ). The top five is further complemented by media sources such as TV news, TV documentaries and newspapers/magazines. In general, more Belgian than Swedish parents reported the presence of donor conception in society. The difference was significant at $p<0.05$ for 'conversation', TV news' and 'TV documentaries'.
Table 1. Characteristics of Belgian and Swedish participants.

\begin{tabular}{|c|c|c|}
\hline & $\begin{array}{c}\text { Belgium } \\
n(\%)\end{array}$ & $\begin{array}{c}\text { Sweden } \\
n(\%)\end{array}$ \\
\hline \multicolumn{3}{|l|}{ Gender } \\
\hline Female & $84 / 89(94.4)$ & $56 / 56(100)$ \\
\hline Male & $5 / 89(5.6)$ & - \\
\hline Age (Mdn-range) & $37(25-61)$ & $41(28-58)$ \\
\hline \multicolumn{3}{|l|}{ Sexual orientation } \\
\hline Heterosexual & $51 / 89(57.3)$ & $36 / 56(64.3)$ \\
\hline Non-heterosexual ${ }^{\mathrm{a}}$ & $38 / 89(42.7)$ & $20 / 56(35.7)$ \\
\hline \multicolumn{3}{|l|}{ Who answered the survey } \\
\hline Genetic parent & $56 / 73(76.7)$ & $45 / 56(83.3)$ \\
\hline Social parent & $17 / 73(23.3)$ & 9/56 (16.7) \\
\hline \multicolumn{3}{|l|}{ Family-type } \\
\hline One parent - family & $30 / 89(33.7)$ & $42 / 56(75)$ \\
\hline Two parent - family & $59 / 89(66.3)$ & $14 / 56(25)$ \\
\hline \multicolumn{3}{|l|}{ Current parental status } \\
\hline Intending parent ${ }^{\mathrm{b}}$ & $12 / 89(13.5)$ & $2 / 56(3.6)$ \\
\hline Parent & 77/89 (86.5) & $54 / 56(96.4)$ \\
\hline \multicolumn{3}{|l|}{ Type of donation } \\
\hline Sperm donation & 66/77 (85.7) & $47 / 54(87)$ \\
\hline Oocyte donation & $9 / 77(11.6)$ & $1 / 54(1.9)$ \\
\hline Embryo donation & - & $1 / 54(1.9)$ \\
\hline Double donation & $2 / 77(2.6)$ & $5 / 54(9.3)$ \\
\hline \multicolumn{3}{|l|}{ Treatment $^{\mathrm{c}}$} \\
\hline Within own country & 70/79 (88.6) & $10 / 59(16.9)$ \\
\hline Abroad & 9/79 (11.4) & $49 / 59(83)$ \\
\hline \multicolumn{3}{|l|}{ Type of donor ${ }^{c}$} \\
\hline Anonymous & 63/71 (87.5) & 22/56 (40.7) \\
\hline Identifiable & 2/71 (2.8) & $33 / 56(61.1)$ \\
\hline Known & 7/71 (9.7) & $1 / 56(1.9)$ \\
\hline Age of children (Mdn, Range) & 3.5 years $(0-23)$ & 3.5 years $(0-31$ \\
\hline \multicolumn{3}{|l|}{ Donor-conceived siblings ${ }^{\mathrm{d}}$} \\
\hline One child & $39 / 72(54.2)$ & $36 / 54(66.7)$ \\
\hline Children with same donor & $27 / 33(81.8)$ & $13 / 18(72.2)$ \\
\hline Children with different donor & $5 / 33(15.2)$ & $3 / 18(16.7)$ \\
\hline Children with same and different & $1 / 33(3)$ & $1 / 18(5.5)$ \\
\hline $\begin{array}{l}\text { Uncertain about } \\
\text { same/different donors }\end{array}$ & - & $1 / 18(5.5)$ \\
\hline \multicolumn{3}{|l|}{ Disclosure stance } \\
\hline Already started to disclose & $44 / 89(49.4)$ & $43 / 56(76.8)$ \\
\hline Plan to disclosure & $41 / 89(46.1)$ & $13 / 56(23.2)$ \\
\hline $\begin{array}{l}\text { Will not disclosure or not } \\
\text { decided yet }\end{array}$ & $4 / 89(4.5)$ & - \\
\hline
\end{tabular}

a'Non-heterosexual' included the options lesbian, gay, bisexual, uncertain, prefer not to say.

${ }^{b}$ 'Intending parent' included participants who went on a clinic visit (BE $n=5$; SE $n=2$ ), planned home insemination ( $\mathrm{BE} n=3$ ), were on the waiting list (BE $n=3)$ or in treatment but not successful yet (BE $n=1)$.

${ }^{c} n$ can be above total $n$ due to attempts within own country and abroad. $d_{5}$ Belgian data missing.

In response to the subsequent open question asking about their impressions of societal representations, similarities and differences were observed between Belgian $(n=57)$ and Swedish $(n=29)$ parents. In Belgium, three themes were identified equally often (21\%): (i) disclosure (e.g. attention to early disclosure, being open is best, late disclosure creates problems), (ii) donor anonymity (e.g. is donor anonymity best?, the need for information regarding biological parent), and (iii) specific imaging/impressions of donor-conceived families. The latter category included both positive ('they are happy families') and negative representations. Negative images concerned 'pitiable women without a man', 'being an exception', 'being problematic due to negative experiences of donor- 
Table 2. To whom did donor-conceiving parents talk about their family being donor-conceived.

\begin{tabular}{lccc}
\hline & BELGIUM $(n=72) n(\%)$ & SWEDEN $(n=54) n(\%)$ & $p$ \\
\hline Friends & $67(93.1)$ & $53(98.1)$ & N.S. \\
Healthcare professional (doctors, nurses, psychologist, $\ldots)$ & $59(81.9)$ & $44(81.5)$ & N.S. \\
Child's kindergarten teacher & $28(38.9)$ & $33(61.1)$ & 0.018 \\
Teacher & $18(25.4)$ & $20(37)$ & N.S. \\
Other & $45(62.5)$ & $33(61.1)$ & N.S. \\
$\quad$ Family & 9 & 11 & \\
Neighbours & 15 & 11 & \\
Workcolleagues & 14 & 12 & \\
Parents of their children's friends & 8 & 11 & \\
\hline
\end{tabular}

conceived offspring' (e.g. late disclosure experience, offsprings' fight for donor information) or 'ridiculing images' (e.g. examples from soap series/movies were given when talking about donor-conceived families). Specific imaging was the major theme mentioned by Swedish parents (55.1\%). Negative images in Sweden concerned the disapproval of solo-mother families ('a child has a right to have a father', 'selfish women ordering children'). Positives images reflected a change to a more accepting attitude towards solomother families. Both Belgian and Swedish parents mentioned polarized views in the media, where the experiences of donor-conceiving parents were contrasted with the experiences of donor-conceived offspring.

\section{Behaviour of donor-conceiving parents}

The majority of Belgian (74/87; 85.1\%) and Swedish $(54 / 56$; $94.4 \%)$ parents talked to others about donor conception in general as well as including their own story. Parents talked most to friends about the donor conception, followed by healthcare professionals and 'others' (see Table 2). Participants defined 'others' mainly as family, neighbours, colleagues or parents of their child's friends and explained the relationship was close to them or that it was relevant for this person to know. Teachers were least talked to. In the follow-up question parents explained that disclosure to teachers mainly served to explain their family structure (a twomother or one-mother family that deviated from the heterosexual norm, how to address the mothers, how to talk about the absence of a father) so the teacher could support their offspring and react adequately to potential questions.

\section{Societal responses}

Among those parents who had discussed donor conception with others, the topics that friends, healthcare professionals and (kindergarten) teachers most frequently commented on or asked about were disclosure, choosing the donor, desire for a child, using the same donor for siblings and the use of an anonymous donor, with slight variations between the different groups (Table 3). Parents reported receiving the least comments or questions about family-relations and the use of a known or identifiable donor. Overall, Belgian parents significantly more often reported receiving comments/questions from friends and healthcare professionals than did Swedish parents, and this was particularly evident for the topic of disclosure. Frequently participants had added they had not received any questions from healthcare professionals ( $\mathrm{BE} n=8$, SE $n=16$ ), kindergarten-teachers ( $\mathrm{BE} n=6, \mathrm{SE} n=12$ ) or teachers (BE $n=6, \mathrm{SE} n=9$ ) at all.

Both Belgian and Swedish parents reported receiving mainly positive responses from friends, healthcare professionals and (kindergarten) teachers: 'people were positively interested and asked questions' and 'people treated us the same as other families' (BE: between 51.6\%-89.1\%; SE: 26.3\%-90\%). Some parents reported reactions that indicated unease such as 'people didn't know how to respond, or awkward silence' (BE: between 12.5\%-23.4\%; SE: 5.3\%-12\%), while negative or disapproving reactions were rare $(<10 \%)$.

In two open-response questions, participants (BE: 58/78, 74\%; SE: 44/50, 80\%) described what kind of reactions from others they had experienced as supportive or inhibiting when talking about donor conception. Reactions that were perceived as inhibiting reflected a heterosexual two-parent household norm ( $\mathrm{BE} n=17$; SE $n=12$ ) or a norm in which genes were seen as determining parenthood/kinship (e.g. calling the donor 'dad', talking about the 'real' parent, a 'real' child, asking if siblings shared the same donor,) (BE $n=22$; SE $n=12$ ), as well as expressions indicating a lack of knowledge or false beliefs (e.g. children from single parent families or with an anonymous donors will develop problems) (BE $n=11$; SE $n=10$ ). Several parents (BE $n=10$; SE $n=3$ ) mentioned that sensitization/education of lay people about donor conception would be helpful. In contrast, non-judgmental reactions reflecting openness to different family structures ( $\mathrm{BE} n=10$; SE $n=10$ ) were perceived as supportive. 


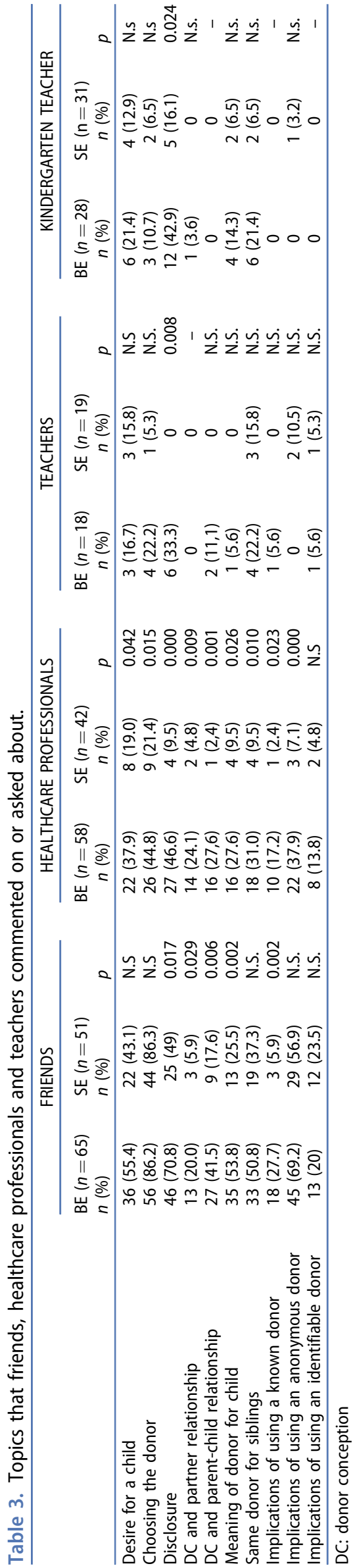

For some parents (BE $n=7 ; \mathrm{SE} n=10$ ) questions about the donor felt rather disturbing. For the Belgian parents this was related to donor anonymity, and the Swedish parents thought this was information that primarily belonged to the child and therefore perceived as crossing privacy barriers.

\section{Attitudes regarding disclosure to others}

In general, both Belgian and Swedish parents felt little reluctance to talk to others about donor conception. There was a significant difference between Belgian parents $(M d n=2)$ and Swedish parents $(M d n=1)$, indicating that Belgian parents felt more uncomfortable to talk to others about their reliance on donor conception due to the association with infertility $(U=1531 ; p=0.006)$ (Table 4). However, an additional analysis including family type (one parent family versus two parent family) showed that this difference was explained by the higher proportion of solo-mothers in Sweden as compared to Belgium.

In a subsequent open-response question, parents could clarify their responses to the above items. Belgian (21/56; 37.5\%) and Swedish (9/37; 24.3\%) parents most frequently said they had no problem talking about donor conception. Sometimes (BE $n=5$; SE $n=3$ ) disclosure was even done purposefully (e.g. to sensitize others and break the taboo for their child, to express their gratitude, because they were proud of their family and sure about their decision). Several factors were mentioned influencing disclosure: the kind of relationship with the other person or the particular context (BE $n=10 ; \mathrm{SE} n=8$ ), the stage of acceptance they were in (BE $n=3$; SE $n=3$ ), being respectfully addressed versus receiving intrusive questions (BE $n=5$; SE $n=8$ ) and the importance of privacy (SE $n=5)$. More Belgian $(n=16)$ than Swedish parents $(n=4)$ referred to taboo and sensitivity of the topic making disclosure challenging. Moreover, for Belgian parents sensitivity was related to infertility and failure, for Swedish parents this was related to the fact that the topic provoked emotional and ethical discussions and polarized views.

\section{Perceived societal attitudes}

The average perceived stigma score for Belgian parents was 2.90 and for Swedish parents 2.73. On item level (See Table 5) parents in both countries scored highest on the experience that people in society did not understand the technology nor the implications of donor conception and that genetic ties 
Table 4. Attitudes regarding talking about donor conception to others.

\begin{tabular}{|c|c|c|c|}
\hline & BELGIUM $(n=77) M d n(M)$ & SWEDEN $(n=55) M d n(M)$ & $p$ \\
\hline It is a private topic which you don't ask questions about. & $5(18.49)$ & $4(22.25)$ & N.S \\
\hline $\begin{array}{l}\text { I feel uncomfortable talking about donor conception because } \\
\text { it is related to sexuality. }\end{array}$ & $2(9.12)$ & $1(8.42)$ & N.S \\
\hline $\begin{array}{l}\text { I feel uncomfortable talking about donor conception because } \\
\text { it is related to infertility. }\end{array}$ & $2(13.83)$ & $1(4.56)$ & $<0.01$ \\
\hline $\begin{array}{l}\text { I feel uncomfortable talking about donor conception because } \\
\text { it is too painful/ sensitive to talk about. }\end{array}$ & $4(14.26)$ & $1(16.25)$ & N.S \\
\hline
\end{tabular}

RATING: 0 : strongly disagree; 100 : strongly agree.

Table 5. Perceived donor conception stigma scores for Belgian and Swedish parents.

\begin{tabular}{|c|c|c|c|c|}
\hline & $\begin{array}{c}\text { BELGIUM } \\
n=68 \\
M(S D)\end{array}$ & $\begin{array}{c}\text { SWEDEN } \\
n=51 \\
M(S D)\end{array}$ & $t$ & $p$ \\
\hline Average Sum score & 2.90 & 2.73 & 1.302 & N.S \\
\hline $\begin{array}{l}\text { People in society think that DC parents - who lack a genetic tie with their } \\
\text { child - are not 'real' parents. }\end{array}$ & $2.4( \pm 1.00)$ & $1.80( \pm 0.87)$ & 3.391 & 0.001 \\
\hline People in society value biological ties over anything else in creating a family. & $3.24( \pm 1.09)$ & $2.92( \pm 1.23)$ & 1.467 & N.S \\
\hline $\begin{array}{l}\text { People in society do not understand donor conception (the technology, } \\
\text { how it is organized and regulated,...). }\end{array}$ & $3.4( \pm 1.20)$ & $3.61( \pm 1.12)$ & -0.978 & N.S \\
\hline $\begin{array}{l}\text { People in society do not understand the psycho-social implications } \\
\text { donor-conceived families have to deal with. }\end{array}$ & $3.53( \pm 0.97)$ & $3.59( \pm 1.08)$ & -0.312 & N.S \\
\hline $\begin{array}{l}\text { People seem less excited about non-genetic families' pregnancies/births (such as } \\
\text { donor-conceived families) than about people's genetic pregnancies/births. }\end{array}$ & $1.93( \pm 1.08)$ & $1.71( \pm 0.97)$ & 1.151 & N.S \\
\hline
\end{tabular}

were very much valued. Belgian parents, compared to Swedish parents, reported a significantly stronger experience that social parents are not 'real' parents within their society.

\section{Discussion}

This study showed that donor-conceiving parents are challenged by societal representations, reactions from friends, healthcare professionals and teachers and cultural norms and values.

Findings in the current study confirm previous reports (Nachtigall et al., 1997; Thorn \& Daniels, 2007) of the presence of perceived stigma, with the level in donor-conceived families being similar to, or above, those faced by adoptive parents (Goldberg et al., 2011). More specifically, donor-conceiving parents perceived that lay people did not understand the technology of donor conception nor the psychosocial implications of donor conception for the family. After talking to friends, health-care professionals and teachers, parents often had to cope with questions about the procedure of donor conception and sometimes with reactions reflecting unease or no response at all. Several researchers have pointed out that a lack of knowledge and understanding within society risks enhancing the feeling of stigma and taboo within donor-conceived families (Klotz, 2013; Shehab et al., 2008; Thorn \& Daniels, 2007). While explicit, straightforward disapproving responses were rare, parents reported being confronted with more subtle remarks revealing 'a culture of genes', which were experienced as inhibiting disclosure. This culture collided with their own views on the importance of genes. Depending on the situation genes can be relevant or irrelevant (Grace \& Daniels, 2007). Thus, parents in this current study perceived genes relevant in a medical situation (e.g. informing healthcare professionals), but irrelevant in the context of family. Yet parents were confronted with a culture in which genes were seen important in relation to kinship/family as experienced through references about the genetic parent being the real parent, asking if siblings have the same donor enabling them to be real siblings and calling the donor 'father'.

As predicted by Steuber and Solomon (2011) participants preferred to disclose within close relationships (friends and family). In addition, Crawshaw and Montuschi (2013) found that donor-conceiving parents felt more confident in disclosing to friends or families than work-colleagues. In relation to health-care workers, the obligation of confidentiality enhanced not only the feeling of trust which promoted disclosure but also the perceived relevance of the information for the parent - health-care worker relationship impacted on parents' disclosure behaviour. As Grace and Daniels (2007) observed, parents perceived it relevant in a medical context to share information regarding donor conception due to the genetic information it contained. In a school-context, parents mainly saw disclosure relevant in case the structure of their family deviated from the heterosexual two parent norm, such as in the situation of solo mother or lesbian families, enabling the teacher to respond adequately to their 
child. No other relevant situations were described. When children grow up, parents can see their child as 'co-owner' of the donor conception information (Blyth, Langridge, \& Harris, 2010) leaving it up to the child if he/she wants to share the information with the teacher/class. Recent reports and findings show that the topic of donor conception can come up in various ways in the school-context (Donor Conception Network 2014, 2017; Indekeu \& Bastiaansen, 2018; Victoria Assisted Reproductive Treatment Authority, 2018) so that it may be valuable for parents to reflect on, and discuss, disclosure within a school-context enabling their child to anticipate school-situations.

Being confronted with lack of knowledge and understanding and a culture of genetic kinship made interacting with others quite challenging. Parents felt they had, among other things, to explain their familybuilding, correct information and defend their choice and/or view. Moreover, the topic of donor conception was experienced as sensitive and intense, due to the emotions it provoked and the ethical questions it raised. This sensitivity and intensity of the topic could make communication quite demanding for parents. Lastly, as Campbell (2011) and Crabb and Augoustinos (2008) demonstrated, media framing - referring to the manner in which the media and the public represent a particular topic or issue (Reese, 2001) - can influence social perception or public discourse. Parents in this study were aware of and needed to cope actively with media framing regarding ART and/or donor conception. Thus, it seemed that parents had continuously to assess their own competence, ability and confidence (e.g. in handling emotions, colliding views, formulating a defence...) in managing these interactions with their social environment.

This study included findings from two countries. While similarities between the countries strengthened the findings with regard to the societal challenges donor-conceiving parents experience, the observed differences pointed to the influence of specific cultural elements as well as differing donor conception regulations. It should be noted that the majority of Swedish participants became solo mothers by donor conception at a time (prior to 2016) when single women could not access ART legally in Sweden and went abroad for their treatment. It was therefore to be expected that Swedish parents reported a greater need to defend their choice of donor conception than Belgian parents. They described frequent experiences of negative societal imaging. A high percentage of these Swedish women also opted for an anonymous donor abroad, when donor anonymity in their home country was abolished. While it could be hypothesized that choosing a type of treatment/donor that was not legally accepted in their home country would raise more questions from society, this was not reflected in the data. On the contrary, Belgian parents received more questions overall than Swedish parents, and questions about the donor were in both countries in the top three most frequently discussed topics. While we had expected some influence of the specific donor conception policy of each country, this turned out to be very limited. Both Belgian and Swedish parents reported a lack of knowledge about donor conception policies among friends, health-care professionals and teachers, limiting the impact of the respective country's policy on social reactions expressed. However, the general trend that Belgian parents received more questions than Swedish parents could point to a difference in existing cultural behaviour patterns (such as norms about what is appropriate when asking personal questions and privacy boundaries) that has guided friends', health-care professionals' and teachers' response behaviour. Finally, Belgian parents seemed more confronted with a culture of genetics, as has been previously described by the Belgian Advisory Committee on Bioethics (2004) and Somers et al. (2015).

The present study had several limitations which impacted on the findings and need to be borne in mind when interpreting the results. Firstly, because most respondents were genetic parents and women the present findings cannot be simply generalized to social parents or men as they may experience stigma regarding their family-building differently due to cultural norms and gender differences regarding parenthood. For future studies, it is important to try and involve men and social parents in this type of research so that their concerns are recognized and taken into account. Secondly, most Swedish participants were solo mothers. Similar to same-sex donor-conceived families, solo mother families are visibly deviating from the heterosexual two parent family. Such aspects might have influenced their experiences additionally. Online surveys are a valuable research tool as they provide an opportunity to reach larger number of families and participants can participate anonymously, yet they do not provide information on representativeness of the sample. Despite these limitations, the present study can offer some insight into the challenges donor-conceiving parents experience when being open to others about their family-building.

This study shows that donor-conceived families in the main do not only need to cope with intra-familial 
challenges but also with societal challenges, such as a lack of knowledge and understanding of donor conception and colliding views on the relevance of genes in relation to kinship. Health-care professionals can play a pivotal role in helping (intending) donor-conceiving parents come to resolution with the challenges of donor conception. While in the past the focus may have been mainly on intra-familial factors influencing disclosure and the family's well-being, the present findings show the importance of including societal factors into counselling. Through psycho-education health-care professionals can help families anticipate potential reactions and manage societal responses by strengthening parents' coping mechanisms. This psycho-education can be integrated in implications counselling (Blyth, 2012; European Society for Human Reproduction and Embryology, 2001) that can take place pre-treatment or at any later point, for example during workshops on disclosure. Lastly, awareness and sensitivity for cultural issues is seen as part of good counselling in cross-cultural counselling (Hynie \& Hammer Burns, 2006). The findings of this study call for equal awareness of the presence of norms and values even when counsellor and patient share the same culture. Given that counsellor and donor-conceiving parent can relate differently to (collide or conform with them) the shared cultural norms, which can impact on their experience, counsellors should be conscious of the norms in their culture and their impact through reflection.

\section{Disclosure statement}

No potential conflict of interest was reported by the authors.

\section{Funding}

This work was supported by the Swedish Research Council for Health, Working Life and Welfare (FORTE) and cofounded by the European Commission (Grant Registration No. 201501227). This work was also supported by the Swedish Research Council.

\section{References}

Adrian, S.W. (2010). Sperm stories: Policies and practices of sperm banking in Denmark and Sweden. European Journal of Women's Studies, 17, 393-411. doi: 10.1177/ 1350506810378078.

Becker, G.A., Butler, A., \& Nachtigall, R.D. (2005). Resemblance talk: A challenge for parents whose children were conceived with donor gametes in the US. Social Science \& Medicine, 61, 1300-1309. doi: 10.1016/ j.socscimed.2005.01.018.
Belgian Advisory Committee on Bioethics. (2004). Recommendation $\mathrm{n}^{\circ} 27$ regarding sperm donation and oocyte donation. https://www.health.belgium.be/nl/adviesnr-27-donatie-van-sperma-en-eicellen, 2018 (accessed 23 May 2018).

Birenbaum-Carmeli, D. (2010). Genetic relatedness and family formation in Israel: Lay perceptions in the light of state policy. New Genetics and Society, 29, 73-85. doi: 10.1080/ 14636770903561380.

Blyth, E. (2012). Guidelines for infertility counselling in different countries: Is there an emerging trend? Human Reproduction, 27, 2046-2057. doi: 10.1093/humrep/des112.

Blyth, E., Langridge, D., \& Harris, R. (2010). Family building in donor conception: Parents' experiences of sharing information. Journal of Reproductive and Infant Psychology, 28, 116-127. doi: 10.1080/02646830903295018.

Campbell, P. (2011). Boundaries and risk: Media framing of assisted reproductive technologies and older mothers. Social Science \& Medicine, 72, 265-272. doi: 10.1016/ j.socscimed.2010.10.028.

Crabb, S., \& Augoustinos, M. (2008). Genes and families in the media: Implications of genetic discourse for constructions of the 'family'. Health Sociology Review, 17, 303-312. doi: 10.5172/hesr.451.17.3.303.

Crawshaw, M., \& Montuschi, O. (2013). Participants' views of attending parenthood preparation workshops for those contemplating donor conception parenthood. Journal of Reproductive and Infant Psychology, 31, 58-71. doi: 10.1080/02646838.2012.748886.

Crawshaw, M., \& Montuschi, O. (2014). It 'did what it said on the tin' - Participants' views of the content and process of Donor Conception Parenthood Preparation Workshops. Human Fertility, 17, 11-20. doi: 10.3109/ 14647273.2014.881562.

Daniels, K., Thorn, P., \& Westerbrooke, R. (2007). Confidence in the use of donor insemination: An evaluation of the impact of participating in a group preparation programme. Human Fertility, 10, 13-20. doi: 10.1080/ 14647270600973035.

Donor Conception Network. (2014). The young people's panel share their experiences and thoughts on our new publication and more. DCN Journal, 10, 7-12. https:// www.denetwork.org/

Donor Conception Network. (2017). Five go to Bristol. DCN Journal, 17, 8-13. https://www.denetwork.org/

ESHRE Task Force on Ethics and Law. (2002). III. Gamete and embryo donation. Human Reproduction, 17, 1407-1408. doi: 10.1093/humrep/17.5.1407.

Ethics Committee of the American Society for Reproductive Medicine (2004). Informing offspring of their conception by gamete donation. Fertility \& Sterility, 81, 527-531. doi: 10.1016/j.fertnstert.2003.11.011.

European Society for Human Reproduction and Embryology. (2001). Guidelines for counselling in infertility. https:// www.eshre.eu/Specialty-groups/Special-Interest-Groups/ Psychology-Counselling/Archive/Guidelines.aspx, 2001 (accessed 1 August, 2018)

Finkler, K. (2001). The kin in the gene: The medicalization of family and kinship in American society. Current Anthropology, 42, 235-263. doi: 10.1086/320004.

Franklin, S. (2013). Biological relatives: IVF, stem cells, and the future of kinship. Chapel Hill: Duke University Press. 
Gannon, K., Glover, L., \& Abel, P. (2004). Masculinity, infertility, stigma and media reports. Social Science \& Medicine, 59, 1169-1175. doi: 10.1016/j.socscimed.2004.01.015.

Goldberg, A.E., Kinkler, L.A., \& Hines, D.A. (2011). Perception and internalization of adoption stigma among gay, lesbian, and heterosexual adoptive parents. Journal of GLBT Family Studies, 7, 132-154. doi: 10.1080/ $1550428 X .2011 .537554$.

Golombok, S., Brewaeys, A., Cook, R., Giavazzi, M.T., Guerra, D., Mantovani, A., ... Dexeus, S. (1996). Children: The European study of assisted reproduction families: Family functioning and child development. Human Reproduction, 11, 2324-2331. doi: 10.1093/oxfordjournals.humrep.a019098.

Grace, V., \& Daniels, K. (2007). The (ir)relevance of genetics. Engendering parallel worlds of procreation and reproduction. Sociology of Health \& Illness, 29, 692-710. doi: 10.1111/j.1467-9566.2007.01010.x.

Gunnarsson-Payne, J. (2016). Grammars of kinship: Biological motherhood and assisted reproduction in the age of epigenetics. Signs, 41, 483-506. doi: 10.1086/684233.

Hahn, S.J., \& Craft-Rosenberg, M. (2002). The disclosure decisions of parents who conceive children using donor eggs. Journal of Obstetric, Gynecologic, \& Neonatal Nursing, 31, 283-293. doi: 10.1111/j.1552-6909.2002.tb00050.x.

Hargreaves, K., \& Daniels, K. (2007). Parents dilemmas in sharing donor insemination conception stories with their children. Children \& Society, 21, 420-431. doi: 10.1111/ j.1099-0860.2006.00079.x.

Hennink, M., Hutter, I., \& Bailey, A. (2011). Qualitative research methods. London: Sage.

Holohan, S. (2012). 'We're a very normal family': Representing the mundane in Channel 4's The Family. Media, Culture \& Society, 34, 21-35. doi: 10.1177/ 0163443711427197.

Hudson, N., Culley, L., Rapport, F., Johnson, M., \& Bharadwaj, A. (2009). 'Public' perceptions of gamete donation: A research review. Public Understanding of Science, 18, 61-77. doi: 10.1177/0963662507078396.

Human Fertilisation and Embryology Act. (2008). Human Fertilisation and Embryology (HFE) Act 1990 as amended in 2008. Section 14, 6C https://www.legislation.gov.uk/ ukpga/2008/22/contents, 2018, (accessed 23 May 2018).

Hynie, M., \& Hammer Burns, L. (2006). Cross-cultural issues in infertility counseling. In S.N. Covington \& L. Hammer-Burns (Eds.) Infertility counseling. A comprehensive handbook for clinicians (pp. 61-82). New York, NY: The Parthenon Publishing Group.

Indekeu, A., \& Bastiaansen, L. (2018). Aanwezig en Afwezig: De Inclusie van Families na Donorconceptie in de Schoolcontext vanuit het Perspectief van Leerkrachten en Zorgcoördinatoren [Present and Absent: Inclusion of donor-conceived families in the school context from a teachers' and school support staff's perspective]. [special issue]. Pedagogiek, 38, 223-255. doi: 10.5117/ PED2018.2.007.INDE.

Indekeu, A., Dierickx, K., Schotsmans, P., Daniels, K.R., Rober, P., \& D'Hooghe, T. (2013). Factors contributing to parental decision-making in disclosing donor conception: A systematic review. Human Reproduction Update, 19, 714-733. doi: 10.1093/humupd/dmt018.
Kirkman, M. (2008). Being a 'real' mum: Motherhood through donated eggs and embryos. Women's Studies International Forum, 31, 241-248. doi: 10.1016/j.wsif.2008.05.006.

Klotz, M. (2013). Genetic knowledge and family identity: Managing gamete donation in Britain and Germany. Sociology, 47, 939-956. doi: 10.1177/0038038513501729.

Lalos, A., Gottlieb, C., \& Lalos, O. (2007). Legislated right for donor-insemination children to know their genetic origin: A study of parental thinking. Human Reproduction, 22, 1759-1768. doi: 10.1093/humrep/dem063.

Nachtigall, R., Tschann, J., Quiroga, S.S., Pitcher, L., \& Becker, G. (1997). Stigma, disclosure, and family functioning among parents of children conceived through donor insemination. Fertility \& Sterility, 68, 83-89. doi: 10.1016/ S0015-0282(97)81480-X.

Nordqvist, P., \& Smart, C. (2014). Relative strangers. Family life, genes and donor conception. p. 8. Hampshire: Palgrave Macmillan.

Reese, S.D. (2001). Introduction. In S. D. Reese, O. H. Gandy, \& A. E. Grant (Eds.), Framing public life: Perspectives on media and our understanding of the social world (pp. 1e31). Mahwah, NJ: Erlbaum.

Strathern, M. (1992). Reproducing the future: Essays on anthropology, kinship and the new reproductive technologies. Manchester: Manchester University Press.

Shehab, D., Duff, J., Pasch, L.A., Mac Dougall, K., Scheib, J.E., \& Nachtigall, R.D. (2008). How parents whose children have been conceived with donor gametes make their disclosure decision: Contexts, influences, and couple dynamics. Fertility \& Sterility, 89, 179-187. doi: 10.1016/ j.fertnstert.2007.02.046.

Somers, S., Ravelingien, A., Provoost, V., Raes, I., Van Parys, H., Wyverkens, E., ..., De Sutter, P. (2015). O-138. Using the same donor for siblings: What it means to parents. Human Reproduction, 30, i60. doi: 10.1093/humrep/ 30.Supplement_1.1.

Söderström-Anttila, V., Sälevaara, M., \& Suikkari, A.M. (2010). Disclosure decisions in families with oocyte donation children born during a 15-year period. Human Reproduction, 25, 2535-2542. doi: 10.1093/humrep/deq194.

Steuber, K.R., \& Solomon, D.H. (2011). Factors that predict married partners' disclosure about infertility to social network members. Journal of Applied Communication Research, 39, 250-270. doi: 10.1080/ 00909882.2011 .585401$.

The Genetic Integrity Act. (2006). Swedish Code of Statutes no 2006:351 Ministry of Health and Social Affairs

Thorn, P., \& Daniels, K. (2007). Pro und Contra Kindesaufklärung nach donogener Insemination - Neuere Entwicklungen und Ergebnisse einer explorativen Studie [Arguments for and against information sharing in families created with the help of DI - Recent developments and the results of an exploratory study]. Geburtshilfe Und Frauenheilkunde, 67, 993-1001. doi: 10.1055/s-2007965582.

Victoria Assisted Reproductive Treatment Authority. (2018). Fertility and Assisted Reproduction: Teaching Module. https://www.varta.org.au/resources/publications/fertility-andassisted-reproduction-teaching-module, 2018, (accessed 23 May 2018). 